\title{
Classic University as Institutional Form of Human Action
}

\author{
Olena Pavlova
}

\author{
Doctor of Philosophical Sciences, Professor, \\ Taras Shevchenko National University of Kyiv \\ (Kyiv, Ukraine) \\ E-mail: invinover19@gmail.com \\ ORCID: 0000-0002-0593-1336
}

\begin{abstract}
The article is devoted to the analysis of historical dynamics of university and its way of organization of human action. The main part of attention is concerned over the classic model of university and its transformations. The university carries out a social institution. It has absence of its own autonomous field of culture, which is a form of spiritual rather than social production. Education is a set of social institutions that produce social structure directly, that is, social technology with the purpose of human and social production of the new model. The society of the late Modern becomes a collection of social institutions (not only educational, but also legal, political, economical, and even in a certain sense cultural) and industries (specialized fields of material production). Education in this sense is a form of human production in general, while economics, politics and law are generally aimed at the indirect production of people through the logic of much complicated institutes movement: economics, politics, law (goods, power structures and laws). Depending on the national model of education, universities determine the priority of certain educational strategies. The university as a social technology, based on the new sample of anthropological model, forms disciplinary practices that function for production of habitus and cultural capital, and also provides identification "under the auspices of the concept of culture" in the Modern era. This cultural-historical period is characterized by the fact that social control is carried out not through personal coercion, but through the passage through institutions. A higher educational institution in the era of Modernity is the most consistent embodiment of the idea of a social institution as an intermediary between spiritual and material production. Culture in this context acts as a form of "high culture," that is, as a way of human existence just like this, with value orientations on the foundations of universal cult of reason. The "Cultural Mission" of the University is a mediation between the regulatory ideas of the Modern and a certain type of state that is, to be a social technology of nation-building. The technology of cultivating reason is provided by studying at the Philosophical Faculty and is an obligatory philosophical component for other faculties in the German model, created by Wilhelm von Humboldt. The formation of the cult of universal reason and self-sufficient subject is the basic task of the classical university and its leading socio-cultural function and cultural mission.
\end{abstract}

Keywords: human action, university, classic university, Modern, social institute, cultural field, disciplinary practice, discourse.

Received January 30, 2018; accepted March 13, 2018

Future Human Image, Volume 9, 2018:

DOI: $10.29202 / \mathrm{fhi} / 9 / 9$

(C) Pavlova, Olena, 2018 


\section{Introduction}

Contemporary cultural transformations make significant corrections to all present sociocultural configurations. A university as the basic phenomenon of Modern is not standing outside of these changes. Pessimistic scenarios declare "death" and "destruction" as the most obvious prospects of its future. In the meantime, the most optimistic, on the contrary, anticipate increasing of its cultural potential in the context of knowledge economy development. The fact that socio-cultural functions of a university are changing in the "post-national constellation"[Habermas, 2001] is supposed as to be generally accepted. The above mentioned fundamental shifts require clarification and explanation of the historical dynamics of higher education institutions, in particular the cultural mission of its classical model. Since the experience of a corporation that successfully survived several civilizational transformations causes respect and as well as both theoretical and practical interest. The task of our research is to determine the cultural mission of the University classical model.

\section{Social and cultural context}

The classical European philosophy of consciousness was based on the universality of the identity principle on the condition of immanent unity of being and thinking. The autonomy of the transcendental subject correlated with the isolation of a man from social conditions of his life and the opposition of the forms of high culture. The unity of the subject itself was carried out in the epistemological dimension on the basis of the intellect universalism as the necessary moment of the realization of its autonomy. All this was a symptom of a shift in the sphere of social self-production.

In the Modern era, the production of the subject was carried out not through the personal compulsion, as in previous eras, but through opposition to the swap of things logics as goods and gradually shifted to the sphere of "passing through the institutes" [Readings, 1997: 44]. The establishment of a market economy and a national state was not independent, but appeared to be the only one socio-cultural process. The modern technology of social production was not just a derivative from the syncretism of material and spiritual culture, but mediated the relationship between industrial production and forms of high culture, the social division of labor, and an organic type of solidarity. Forms of high culture required the body of social structures, on the one hand, and, on the other hand, the industrial and economic spheres were the result of the subjects interaction as atomic individuals, which were caused by their relations with things. Industry demanded the economy specialization, legal and political systems for its successful functioning, which led to the formation of institutions derived from the sectoral division of the industry. At the same time, another type of social activity separated - social technology itself (that was out of the specialization of the material and spiritual spheres of production).

On the first place, it was the sphere of education. The last one serves as a technology for the formation of a person in a complex differentiated society, where the reproduction of social opportunities of every one is carried out significantly outside of his belonging to the occupations in his family and genus in general. Education is a social lift, social magic, exit beyond the three classical stratums of the Indo-Europeans (oratores, bellatores, laboratories).

University as a form of higher education becomes the basic institute of the Modern, it is the crossing of its two main dimensions: the academic corporation and the state institution. It should 
be noted that the first appointment was initially self-sufficient. Moreover, all corporations were carried out as universitas, that is, as a community of equal people who had vowed each other. This was the union of any craft guild and even the city community as a whole, the prototype of any institute in the modern sense of the word, and even a legal person, as being proved by the studies of the medievalists. Only gradually such a name was fixed only for a certain type of educational institutions.

We should not also forget about the religious-ritual dominant of any premodern civilization. In the statutes of the first universities, in particular Parisian one in the $13^{\text {th }}$ century, it was recorded that they were "a community of the alive and the dead" [Oexle, 2007: 27]. This meant, first of all, the responsibility for the funeral ceremonies of community members and funeral prayers for them. Since being detached from blood relatives, students and even lecturers usually stayed in a foreign country without support, in such an important for religious people thing as funeral and memorial. The rituality of the last ones was even obligatory for Christianity, despite the high degree of theology rationalization. Consequently, in pre-modern Europe, the university was born as a transnational corporation based on the principles of the civilization of Christian Europe unity and the organizational - Papal Curia. However, the first change of the Reformation, and then secularization, allowed it to be nationalized quickly.

\section{Classic university: between disciplinary practice and discourse}

The construction of a national state required an increase in the bureaucracy and, accordingly, an educated class of people. Time has shifted accents. University autonomy, which took its origins in the codes of guilds, gradually began to serve as a necessary social distance from the utilitarian cares of life in order to create an appropriate anthropological model.

The social function of the university was explained by Immanuel Kant in the well-known work "the Conflict of the Faculties." He said that the state as a source of financing uses the product of university education - educated people. The last ones are needed "to influence the people by certain teachings" [Kant, 2002]. Influence becomes possible due to the fact that people are lost in the contradiction between their sensual impulses, private goods and social requirements. They do not want to be responsible for every decision and want to be led in the most enjoyable and safe ways. What the state did through the community of not professional scientists, but educated people who represented "motivation reasons" to coordinate the interactions between individuals and, more importantly, with the state. Immanuel Kant emphasizes that "according to reason (that is, objectively) the following order exists among the incentives that the government can use to achieve its ends (of influence the people): first comes the eternal well-being of each, then his civil well-being as a member of each society and, finally, physical well-being (a long life and health)" [Kant, 2002]. Each of these "incentives" had a projection of the socio-cultural system of the Modern and a psychological coloration that represents private space of the atomized individual. After all, person of Modern is connected with the social whole by private interest. "Eternal well-being" is a private dimension of spiritual culture; "physical well-being" was a condition of material, even physical reproduction of an individual. "Civil well-being" — this is a form of the evolving of private interest in the general legal system of self-production of society. Each of these areas is a combination of disciplinary practices in Foucauldian description (first and foremost, medicine and law). The last ones were devoted to create the conscience as the "body of the prison," that was, "by teachings regarding the second (civil well-being) it (government) helps to keep their external conduct under their 
reins of public law" [Kant, 2002]. Modern disciplinary practices, their norms and rules, differ both from the types of institutionalization of the human actions in Premodern, and from the value orientations of cultural fields.

In the dimension of high culture there was a certain number of fields producing a priori values and "the system of things", which are intended to legitimize the self-sufficiency of each of them (in case of art and science). In the body of society such cultural fields incorporate through social institutions. The last ones have the middle function: to preserve the a priori status of values and to form the productions and consumers of them, that was to deal directly with the actors as their agents. For the incorporation of subjects into social structure of cultural field disciplinary technologies are being produced, which, in the process of learning and obsessing, turn into habitus (body techniques) and cultural capital (an interiorized set of knowledge and values), in the bourdieusian concept. Modern body typification techniques and their legitimation in public perception as generally recognized lead to the formation of disciplinary practices. Fundamental difference was in Eliasian perspective.

The Formation of social structures that provide the implementation of these disciplinary practices is the process of institutionalization. The emergence of a certain set of knowledge, the content which determines the form of its implementation, also causes a certain style, a certain way of thinking. The functioning of such knowledge as a cultural capital was a form of implementation of discursive practices. They supplement disciplinary practices and even gradually begin to provide reflation over them, organize them, asking for models and norms for the last ones. The autonomy of the theoretical sphere sets authority and level of recognition of discursive practices and becomes the basis of their ideology. Thus, the role of discourse and ideology in the process of institutionalization of Modern is much higher than in previous historical types of culture. On the autonomy of the theoretical consciousness itself and the spiritual forms of culture is generally based on the specificity of the social institutes of the Modern age.

The process of person incorporating into the body of a social institution is the most successful when it is not just a bad imitator (that is the difference between a simple which is produced by a cultural field and its unsuccessful bearer becomes obvious), but when a person becomes the creator of socio-cultural norms and even the institution, that is, it promotes the autonomy of the cultural field and / or its financial success. In fact, the producing of disciplinary practices is a condition of obsessing them as a separate subject, that is, the moment of selfproduction of the cultural field itself in a social dimension. The dualism of habitus and cultural field capital and of the institute as its basic social structure is sufficiently stable in the context of the domination of a closed type of cultural field, for example art production. The university is a more pure form of a social institute than social structures of the art field. In order to clarify this problem, one should turn to the incomplete problem of the institute.

British researcher Raymond Williams in his work "Keywords vocabulary of culture and society" concluded, that "Institution is one of several examples of a noun of action or process which became, at a certain stage, a general and abstract noun describing something apparently objective and systematic; in fact, in the modern sense, an institution" [Williams, 1983: 168] in the dimension of human interaction.

Human activity always makes sense and obeys a certain established rule or order. This sense of installation is very important. After all, the use of the term "institute" in English language in the $14^{\text {th }}$ century had a connotation of 
"establish, found, appoint. In its earliest uses it had the strong sense of an act of origin something instituted at a particular point in time - but by $16^{\text {th }}$ century there was a general developing sense of practices established in certain ways, and this can be read in a virtually modern sense: 'in one tongue, in like manners, institutions and laws (Robinson's translation of More's Utopia, 1551); 'many good institutions, Lawes, manners, the art of government' (Ashley, 1594). But there was still, in context, a strong sense of custom, as in the surviving sense of one of the institutions of the place" [Williams, 1983: 168].

British law still has retained the peculiarities of the case-law of its application, in contrast to universal and rational shifts in its French interpretation of it, up to the requirement of the Declaration of Human Rights. In this, the emergence of a conflict between the aristocratic respecting of tradition and the democratic nature of the enlightenment critique of tradition was considered as a superstition.

Raymond Williams notes the complexity:

"to date the emergence of a fully abstract sense; it appears linked, throughout, with the related abstraction of society. By $18^{\text {th }}$ century an abstract sense is quite evident, and examples multiply in $19^{\text {th }}$ century and $20^{\text {th }}$ century. At the same time, from $18^{\text {th }}$ century, institution and, later, institute (which had carried the same general sense as institution from $16^{\text {th }}$ century) began to be used in the titles of specific organizations or types of organization: 'Charitable Institutions' (1764) and several titles from $18^{\text {th }}$ century; Mechanics' Institutes, Royal Institute of British Architects, and comparable organizations from $18^{\text {th }}$ century here probably imitated from the Institute National, created in France in 1795 in consciously modern terminology. Institute has since been widely used for professional, educational and research organizations; institution for charitable and benevolent organizations. Meanwhile the general sense of a form of social organization, specific or abstract, was confirmed in $19^{\text {th }}$ century development of institutional and institutionalize. In $20^{\text {th }}$ century institution has become the normal term for any organized element of a society" [Williams, 1983: 168].

It is worth mentioning, that data of Raymond William's definition are rather descriptive, but they enlighten the historical dimension of the question.

\section{Human action and Modern organization of social institute and cultural field}

The logic of making ordinary, "typicality" of human action, which comprises the functions of its objectification and legitimation, is put into the basis of the consideration of the institutionalization of human life in the sociological works. Significantly higher degrees of unification and rationalization of the institutes of Modernity is supposed. A new form of myth of Modern society (D. Meyer, B. Rowen) [Meyer \& Rowen, 1977: 340] and its ceremonies in the form of self-compel and self-control is also noted by researchers as a modern feature. The specificity of the institutes of Modern consist of using disciplinary practices that, by help of the internalization of certain behavior codes, creates the new technology of social production of man. After all, the Modern institute is controlled not only by its own mechanism of implementation, and not even by additional sanctions (such as completion or punishment), but created the most productive reflexive model of self-control. The universal cult of mind and, accordingly, the 
Faculty of Philosophy, not only produces the new type of discourse or cultural capital, but also a way of new social formation. Thus, the new anthropological model is produced and also a new social order, where consciousness is formed as an instance which separated from the living conditions and controls it from the outside. Such a sociocultural practice would not have been possible without the experience of Christianity and its confessional procedures. Their influence could already be evident in such early Modern characters as Don Juan and Faust. However, the self-control of Christianity was sent to the authority of God, and therefore autonomy of consciousness could not be implemented consistently. Modern anthropocentrism did not foresee external instances, but itself was rooted in human sensual-rational dualism. The autonomy of theoretical consciousness was provided by disciplinary practices of university education.

The university, for example, as opposed to art, is a social institution itself, in other words it has absence of its own an autonomous field of culture, which is a form of spiritual rather than social production. Education is a set of social institutions that produce social structure directly, that is, social technology with the purpose of human and social production of the new model. The society of the late Modern becomes a collection of social institutions (not only educational, but also legal, political, economical, and even in a certain sense cultural) and industries (specialized fields of material production). Education in this sense is a form of human production in general, while economics, politics and law are generally aimed at the indirect production of people through the logic of much complicated institutes movement: economics, politics, law (goods, power structures and laws).

Depending on the national model of education, universities determine the priority of certain educational strategies. This is generally accepted business orientation of American higher education institutions. In French universities after the Napoleonic reform, a correlation of the interests of the state with social division of labor was implemented. The priority of university autonomy, research programs and the broad humanitarian basis of studying is characterized by the Humboldt model. The more problematic was the collision of the formation of a national state, the more claims model of the university to a greater degree of social disposition. The Humboldt version became a classical form of the university and has spread to many countries around the world, in particular, Ukrainian universities were formed by its model.

Exactly this German model of university has become the object of Immanuel Kant's reflection. The specialization of the faculties, through which the production of this type of educated people is carried out, correlates with the modern form of socio-cultural differentiation. The discursive practices of individual disciplines and faculties become the basis for the identification of professional communities. The University, accordingly, was an institute, an intermediary in the form of a social system between a state machine and atomic individuals. Division, which was formed empirically, on Immanuel Kant's opinion, nevertheless, corresponds to a certain a priori principle. This approach becomes the main one for the cultural sociology represented by Scott Lash [Serani \& Lash, 2016: 3].

All these spheres of privatization of the public good for which the medical, legal and theological facilities are practical, are service and non-self-sufficient, despite their ability to formulate guidelines and dictate orders. They are not able to clarify their own principles, and therefore the basic one for Immanuel Kant was the lower faculty — philosophical — the task of which was "public presentation of truth as its function" [Kant, 2002]. Exactly his impracticality, the inability to formulate orders and to provide bread studying, enables freedom of judgment and truthfulness of knowledge of representatives of other faculties. 
His task is to produce educated people whose "increased insight gained from this freedom, a better means for achieving its ends than its own absolute authority" [Kant, 2002] This means that the universality of reason is a Modern ground for coordinating action, in contrast to Premodern compulsion. Therefore, the resolution of the conflict of the faculties can be either "legitimate" - the recognition of the universal status of reason for the functioning of the national state, or "illegal", which provides a short "heroic way" to the disappearance of the lower faculty.

The explanation for the "Conflict of Faculties", in this regard is the concept of Canadian researcher Bill Readings [Readings: 1997], which proved the connection of this university model being based on the idea of culture, with the structures of the functioning of the national state. Its political discourse is based on the principles of sending to a collective entity, which represents itself as a «species-being». Therefore, the basic task of the national state is the task of implementing the "rational self-determining subject of modernity", that is, a self-sufficient subject. Army, literature and education are socio-cultural technologies of this complicated process. The last can represent school and university. If a school (and even the obligatory elementary education as a whole) has its task to form disciplinary practices that proved to be extremely important for the Modern Dominant of Consciousness the "Techniques of the Body," as well as the level of literacy required for the reserve army of labor and just an army (that is, first of all, caused by the charity of the "social state", a welfare state), the task of creating and reproducing a model of national identity, the bearer of which is a self-sufficient subject becomes exactly the formation of Humboldt's model of the university.

Subjected to an autocratic monarchy was, in the first place, limited (or, conversely, privileged) by rights. There is no wonder that one of the first historical acts of the bourgeois revolution in France was the acceptance of the Declaration of Human Rights. The necessity of the equality of all of people under the law is ensured by the division of power. The subjugation of the Modern subject to the national state was carried out differently from the non-Modern way. In previous times, personal coercion was a dominant form of relations between people and social systems, but gradually the rich form of dependence became the most important. In such a specific situation, the relationship between a man and the state is carried out through the passage of a number of social institutions, the crown of which is the university. "I $£$ can become transcendental, only "passing through the institutes" [Readings, 1997: 44], or much precisely the nation. The Humboldt University model proposed, in contrast to the Napoleonic version and the Hopkins one, has not accidentally deliberately denied the orientation of bread studying or the state's needs, that is, the provision of a profession to be fed after the end of study, but set goal for creating a self-sufficient subject.

\section{Conclusions}

Thus, the university as a social technology, based on the new sample of the anthropological model, forms disciplinary practices that function for production of habitus and cultural capital, and also provides identification "integration and standardization" [Readings, 1997: 29] in the Modern era. This cultural-historical period is characterized by the fact that social control is carried out not through personal coercion, but through the passage through institutions. A higher educational institution in the era of Modernity is the most consistent embodiment of the idea of a social institution as an intermediary between spiritual and material production. Culture in this context acts as a form of "high culture," that is, as a way of human existence just 
like this, with value orientations on the foundations of universal cult of reason. The "Cultural Mission" of the University is a mediation between the regulatory ideas of the Modern and a certain type of state that is, to be a social technology of nation-building. The technology of cultivating reason is provided by studying at the Philosophy Faculty and is an obligatory philosophical component for other faculties in the German model, created by V. Humboldt. The formation of the cult of universal reason and self-sufficient subject is the basic task of the classical university and its leading socio-cultural function and cultural mission.

\section{[D] References}

Habermas, Jürgen. Post-national constellation: Political Essays. MIT Press: 2001.

Kant, Immanuel. The Conflict of the Faculties. 2002. Retrieved from http://la.utexas.edu/ users/hcleaver/330T/350kPEEKantConflictFacNarrow.pdf

Luca Serani, Scott Lash. Cultural Studies and Cultural Sociology. Sociologica. 1, 2016: 11-13.

Meyer, John and Brian Rowan. Institutionalized Organizations: Formal Structure as Myth and Ceremony. The American Journal of Sociology, 83 (2), 1977: 340-363.

Oexle, Otto. Reality and knowledge: Essays on the social history of the Middle Ages. Moscow: New Literary Review, 2007.

Readings, Bill. The University in Ruins. Harvard University Press, Year: 1997.

Williams, Raymond. Keywords: a Vocabulary of Culture and Society. New York: Oxford University Press, 1983. 